\title{
The Mutual Impact of Demand Response Programs and Renewable Energies: A Survey
}

\author{
Neda Hajibandeh ${ }^{1,2}$, Mehdi Ehsan ${ }^{1,3, *}$, Soodabeh Soleymani ${ }^{1}$, Miadreza Shafie-khah ${ }^{2}$ and \\ João P. S. Catalão $2,4,5, *$ \\ 1 Department Electrical \& Computer Engineering, Science and Research Branch, Islamic Azad University, \\ Tehran 14778-93855, Iran; neda.hajibandeh@srbiau.ac.ir (N.H.); s.soleymani@srbiau.ac.ir (S.S.) \\ 2 Center for Mechanical and Aerospace Science and Technologies (C-MAST), University of Beira Interior, \\ 6201-001 Covilhã, Portugal; miadreza@ubi.pt \\ 3 Department Electrical Engineering, Sharif University of Technology, Tehran 11155-8639, Iran \\ 4 Instituto de Engenharia de Sistemas e Computadores, Tecnologia e Ciência (INESC TEC), \\ Faculty of Engineering, University of Porto, 4200-465 Porto, Portugal \\ 5 Instituto de Engenharia de Sistemas e Computadores, Investigação e Desenvolvimento (INESC-ID), \\ Instituto Superior Técnico, University of Lisbon, 1049-001 Lisbon, Portugal \\ * Correspondence: ehsan@sharif.edu (M.E.); catalao@ubi.pt (J.P.S.C.)
}

Received: 4 July 2017; Accepted: 31 August 2017; Published: 7 September 2017

\begin{abstract}
Renewable energies as a solution for environmental issues have always been a key research area due to Demand Response Programs (DRPs). However, the intermittent nature of such energies may cause economic and technological challenges for Independent System Operators (ISOs) besides DRPs, since the acceptable effective solution may exceed the requirement of further investigations. Although, previous studies emphasized employing Demand Response and Renewable Energies in power systems, each problem was investigated independently, and there have been few studies which have investigated these problems simultaneously. In these recent studies, authors neither analyzed these problems simultaneously nor discussed which scientific and practical aspects of demand response and renewable energy injection were employed. Motivated by this requirement, this research has focused on a comprehensive review of recent research of these cases to provide a comprehensive reference for future works.
\end{abstract}

Keywords: renewable energies; demand response programs; electricity market

\section{Introduction}

To increase the sustainability of electrical systems, policy makers have promoted renewable energy technologies. Moreover, concerns about environmental pollution and the ever increasing consumption of fossil fuels in many of the power systems have made generators change their electricity generation paradigm to use more renewable energy resources [1].

Although, in recent decades, the capacity of renewable energy resources has increased significantly, the evolution of conventional power generators to wind generators has proceeded much more. In general, wind and solar energy are the most applicable forms of renewable energies in the power generation plans of power systems. However, wind energy is a novel low-cost energy which has penetrated electrical systems more than other types of energy in recent decades [2].

This type of energy is unpredictable due to its intermittent nature. Besides, possible unpredictable variations in power over a short time are caused by serious challenges. Wind farms can be integrated with Demand Response Programs (DRPs) to reduce side effects of wind fluctuations. The majority of decision makers, power system operators or investors have focused on the advantages and challenges of the proposed DR schemes with specific goals. Therefore motivated by this requisite, this paper 
focuses on recent studies on DRPs associated with renewable energies and the positive and negative aspects of the DR schemes. However, DR systems have not been investigated from this point of view. In [3], a useful summary of DR, benefits and cost was proposed which has also been expanded in this study. Moreover, the number of indices for DR evaluation in the electricity market is presented, and the impact of DR on energy prices is investigated through simulation. However, integrating renewable energies to the network has not been investigated. The most recent review paper on a similar topic is [4] in which successful and effective implementations of DR throughout the world are mentioned, but the current paper has provided a more comprehensive study. Only a few references which include renewable energy resources are mentioned in [4] and this topic was not investigated deeply. Here in this paper, we have tried to fill this gap and emphasize the importance of current challenges and problems for future works. In addition, this paper has investigated various electricity market patterns by considering DR and renewable energy resources and has classified recent studies on the optimization of DRs and renewable energy resources in the energy market. Reference [5], presented a review of system flexibility measures in energy systems with high penetrations of renewable energies. They claimed within that the flexibility of most electrical systems can be handled by the system itself without requiring considerable changes or further investments. In [6], a review of real-time energy markets with distributed energy sources and DR is presented. The valuable real-time market experiences in some parts of the world are also explained.

The main objective of this report is to conduct an extensive and thorough review of recent studies on DR programs in power systems associated with renewable energies specifically wind energy and to explore an appropriate instrument to help system operators in the best way. Acceptable solutions proposed in this context for balancing the electricity market under the mutual effect of DR programs and renewable energy resources and its pros and cons are offered. A systematic review is presented to improve the flexibility of the electricity system to face the integration of renewable energies. Additionally, in order to consider renewable energies and DRPS simultaneously, strategies relevant to these fundamental concepts are also proposed and analyzed.

We looked for solutions that are linked to the demand side, energy power system, power supplies, and the energy markets. The literature on strategies or technologies for electricity system reliability is extensive. In [7], a strong innovation of DR for improving the reliability of the Pennsylvania New Jersey Maryland (PJM) electricity market in North America was proposed in 2014. A qualitative analysis with regard to benefits of the DR is presented.

This paper presents an overview of recent researchers on DRPs and renewable energies. The paper starts with categorization of previous reports, followed by modeling responsive loads, the different markets, and a detailed classification of recent relevant literature and benefits and costs of demand response implementation. Finally, the paper makes its conclusions.

\section{Classification of the Solutions for System Operators}

The uncertainties and fluctuations of renewable power productions compared to conventional power generations may impose serious challenges on power system operators. The unpredictable amount of renewable power generations may lead to the instability of the power systems and an imbalance in the demand-supply equation. To face the uncertainties of renewable energies, several researches have been carried out. To provide a more flexible power system, which has been the main goal in most previous studies, three major solution classifications are proposed for power system operators:

(1) Integration of renewable energies with energy storage systems (ESSs).

(2) Utilizing additional reserve at electricity markets and developing market rules and structures.

(3) Utilizing demand side sources.

The solutions proposed for power system operators to administer a more flexible power grid are illustrated in Figure 1. 


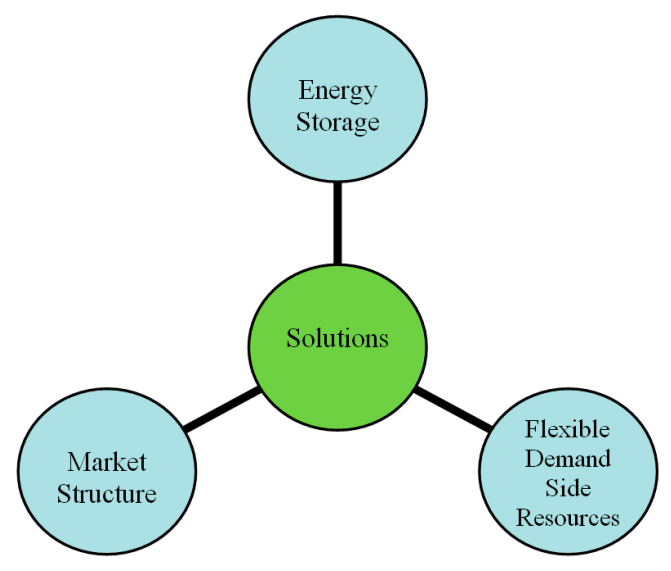

Figure 1. Solutions for power system operators to administer a more flexible power grid.

\subsection{Using Energy Storage Technologies}

In a large part of the literature, integration of renewable energies with ESSs has been suggested. In [8], authors reviewed various reservoirs for wind power applications. Particularly in [9], the thermal reservoir with phase change materials in construction application is reviewed. In addition, in [10], authors enhanced the efficiency of energy storage systems considering high penetration of renewable energies, but further research is required, particularly for large-scale integration of such energies. The mentioned challenges are really complicated, however, this paper has investigated these challenges but the number of considered scenarios is limited.

Authors of [11] investigated the value of integrating compressed air energy storage which is a method for storing high amounts of energy. In order to evaluate a case study in Denmark, the economic benefits obtained using wind farms are compared with the costs of using compressed air energy storage (CAES) technology. The results are compared to other different storage options. A bi-level optimization approach is presented in [12], which optimizes an energy storage operator's bidding strategy for the day-ahead and the following day market. Determining the optimal installation place and the size of storage devices have been widely studied. In [13], a multi-stage method is presented to achieve near-optimal location of the reservoirs and their sizes employed for spatiotemporal arbitrage. Also, applying another type of storage, the hydropower plant, as a generation unit in addition to wind plants is another solution which has been studied for decreasing the fluctuation in wind power generation [14]. In the latest studies, real and large-scale networks are investigated to reveal the impact of renewable energy injection on realistic case studies of the real world practically [15,16]. In [15], a multi-objective problem is solved for a case study of an island in China. Using a hybrid optimization model reduces costs and pollution and energy storage is modeled as a solution. A practical cost reduction percentage was derived by employing flywheels and battery reservoirs.

\subsection{Improving Market Structure}

Another set of papers proposed new market structures as a solution to cover the uncertainty of renewable energies. The mechanism of the market and its structure have become more complex as a result of introducing novel services to face some of the controlling and planning problems of the renewable units generation. To cope with these difficulties a specific type of market design, based on two-part pricing issue, was introduced [17], and contracts [18] employed to receive energy for providing power and reserves. Using these contracts, the system operator forces the market players to deliver their energy to the market while they receive a predetermined amount of payment based on real-time market production.

In [19], the necessity of intraday markets in the presence of wind farms is discussed. The authors evaluated and compared the forecast quality and necessity of flexibility in the power system due to 
the presence of wind energy in five EU countries. Based on [19], the latter investigation depicts that an extra integration of European (EU) Intraday-markets can adversely affect the amount of flexibility required to overcome the forecast errors resulting from the intermittent nature of renewable energies. The results obtained from these two cases were described in [20] which analyzes policy and auction design for energy and reserves to facilitate wind integration.

Other reports for instance [21] analyze additional reserve requirements for flexible integration of wind energy through the electricity market. In [22], authors construct and validate a hidden Markov method for anticipating variability and uncertainties in the production of PV systems. They proposed a model that can be employed as a tool for considering the extra reserve capacity required for balancing solar variabilities. Due to fluctuations of wind generation which depend on the weather condition and wind speed, the deterministic methods are inapplicable. Therefore, many recent reports employed stochastic programming methods [22,23].

\subsection{Using Flexible Demand Side Resources}

The third category in the literature is associated with flexible demand-side resources, for instance, plug-in hybrid electric vehicles and demand side management solutions, specifically demand response [24-26]. Electric vehicles were taken into account as adaptable portable battery storages. Moreover, a two-stage energy scheduling strategy for multiple micro grids was proposed [24]. A model of Plug-in vehicles was designed to discover a strategy to decrease the charging load peak by the considerable amount of $47 \%$ [26]. Measuring the electric vehicle battery degradation was imposed in [25]. The cost of battery degradation and the impact of frequency regulation besides peak load shaving on battery degradation were investigated in the mentioned reference. Electric vehicles were discussed as a problem-solving technique to overcome the imbalance between energy supply and demand in power networks considering the high penetration of renewable energies as underlined in [27]. According to the uncertain variables of renewable energies like wind generation or solar production or charging demand of electric cars, the probability distribution functions of the load are employed [28]. In [29], a novel power management strategy is proposed to cope with inaccuracy and uncertainties of the terrain information with the aim to improve battery life, while maintaining overall system performance. First, the impact of terrain inaccuracy on battery life and system efficiency is analyzed based on two different hybrid ESSs with semi-active topologies. Then, a power management control strategy is developed that actively distributes the power between battery and supercapacitor adapted to terrain inaccuracy and uncertainties. In [30,31], the authors analyzed the role of DRPs in covering wind farm fluctuations in relation to the power system operation. Authors in [31] presented a multi-stage formulation for aggregators and illustrated the reduction in the total costs. In this study only incentive based DRP was modeled and the effect of other kinds of DRPs were not investigated.

Many types of research have examined comprehensively the effects of DRPs on wind integration. Authors of [32] formulated real-time price prediction control in electricity markets through the modeling behavior of market players in both demand and supply sides, renewable energy resources, and independent system operators (ISOs). They formulated an optimization for real-time price to model predictive controllers and then demonstrated the efficiency of such a method through numerical results. Authors of [33] proposed a model to maximize the unnecessary energy of a given consumer that employs wind energy and ESSs. To formulate the function of power consumption, the curve of hourly electricity consumption was investigated. In [34], in order to smooth the load curve and cover the uncertainties and fluctuations of wind integration in the market, an incentive-based DRP was proposed. The DRP proposed in this paper only reduces load while the authors of [35] conducted a more comprehensive study by employing self and mutual elasticity of the price. The mentioned references used deterministic methods while wind energy is stochastic. Accordingly, [36] modeled a two stage Stochastic Constrained Unit Commitment (SCUC) associated with DR and wind farms in which different kinds of DR programs, Time of Use (TOU), Real Time Pricing (RTP), and Emergency Demand Response Program (EDRP) are modeled and are discussed in more detail in the next section. 


\section{Models of Responsive Loads}

On the demand-side, end-users reduce their energy consumption by determining price changes or incentive amount of payment through DR tariffs. The DRPs are categorized into two basic groups, named Price-Based Programs (PBPs) and Incentive-Based Programs (IBPs) [37]. In other literature reports, these two classifications are called system- and market-led, emergency- and economic-based, or stability- and economic-based DRPs [38]. IBPs are separated into two parts named, classical programs and market-based programs. In classical IBPs, the consumers who take part in such programs receive participation payments, usually in the form of a bill or sometimes a discount, because of their participation in the programs. In market-based categories, customers who take part in such programs are rewarded with money which is proportional to the amount of shift in their electricity consumption at peak hours. Figure 2 shows this kind of clustering.

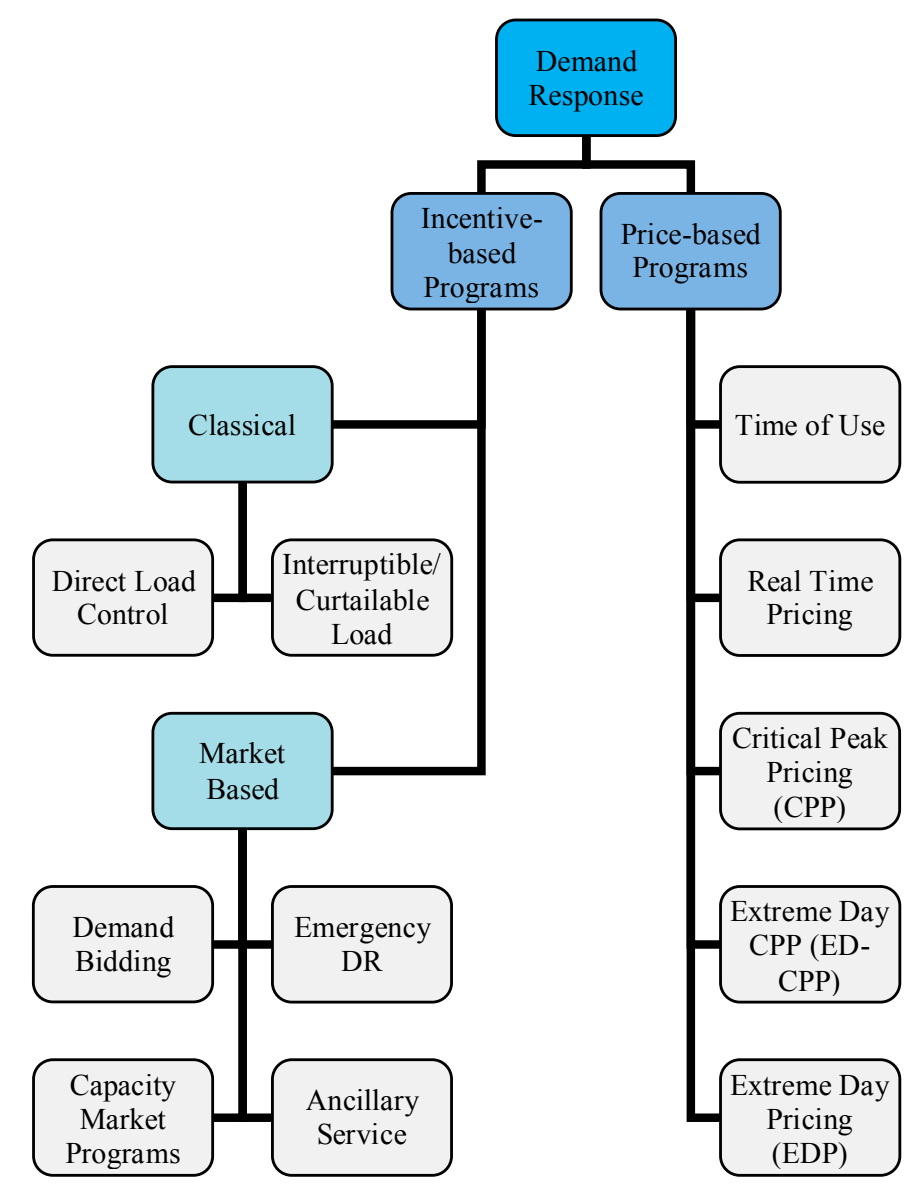

Figure 2. Categories of demand response programs [38].

Each of these groups consists of several programs. These DR programs are discussed thoroughly in [33]. According to the literature, DRPs are also divided into price-based or quantity-based programs. PBDR programs strive to decrease the customer's energy demand through price changes. IBDR programs or Quantity-based programs, strive to reduce end-users demand through direct utility control of the main loads at home such as air conditioners, electric heaters, and/or pumps [34].

Figures 3 and 4 demonstrate this kind of clustering. In order to model the demand-side load, the concept of elasticity of demand is employed in DRPs. Moreover, the detailed and complete economic model of DR programs was improved in [39]. In [40], the requirement of DR programs of having a smooth load curve is indicated. In [40], programs are modeled on both a price-based and an incentive-based DR program. 


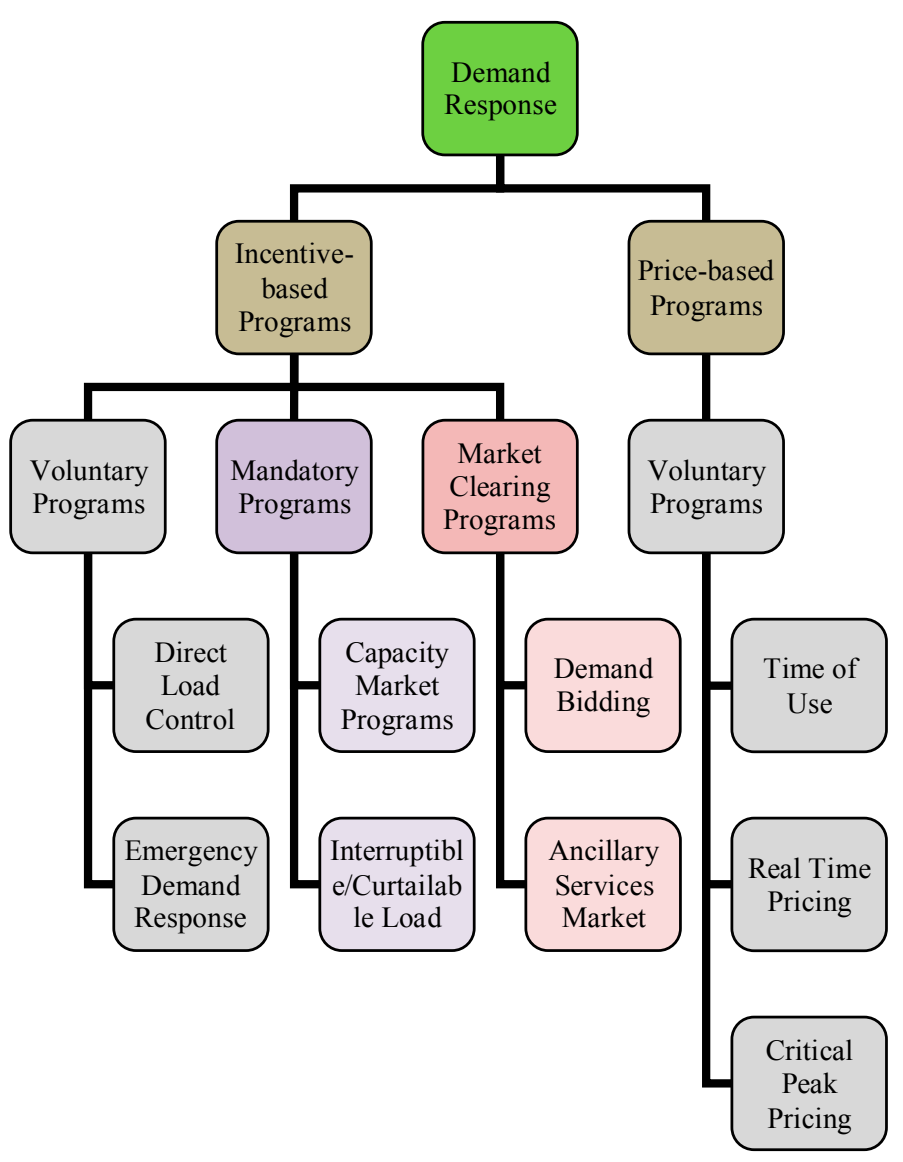

Figure 3. Classification of demand response programs [36].

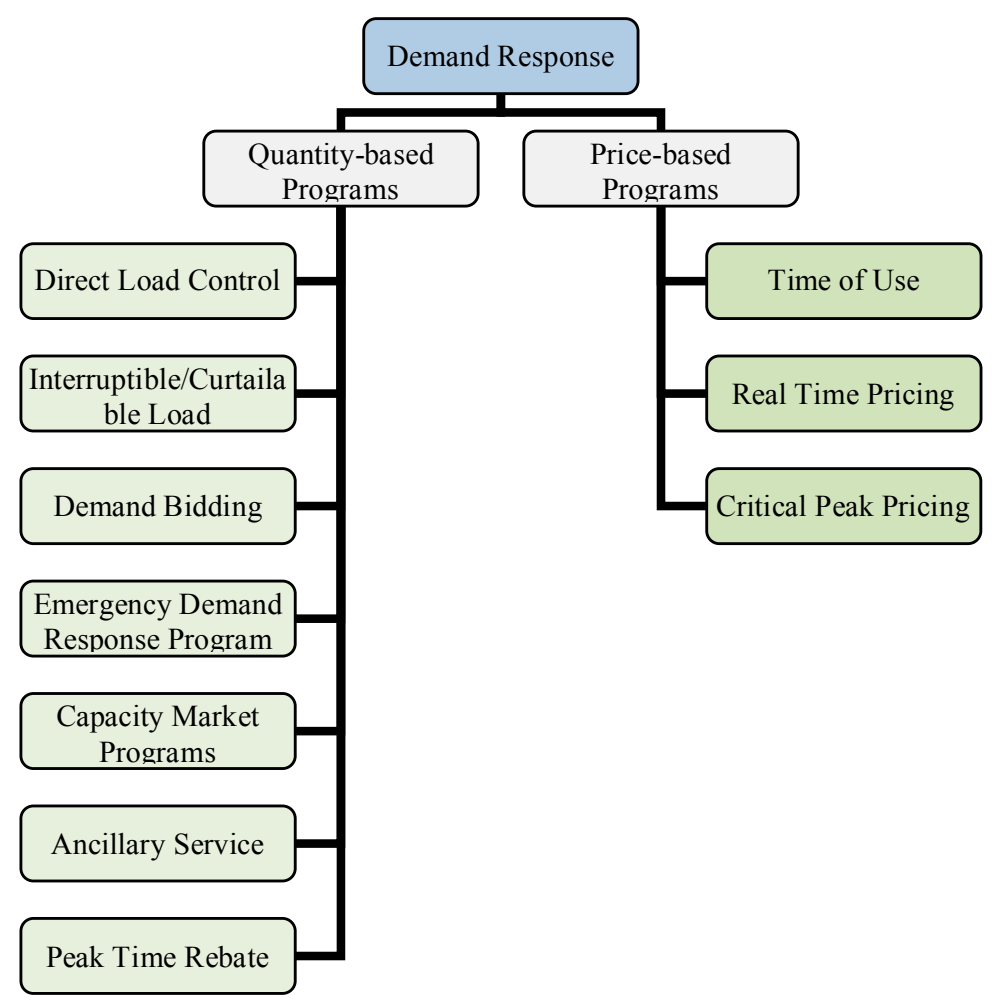

Figure 4. Classification of demand response programs [41]. 
In some reports, definitions and advantages of DR programs in power energy markets are proposed. Authors of [3] proposed a summary of DR in restructured power energy markets. The definition and classification of DR, as well as its positive points along with negative points such as cost factors are discussed.

\section{Various Electricity Market Designs Enabling Demand Response and Renewable Energy Systems}

European electricity markets are mainly day-ahead spot markets which lead to considerable demand for balancing services or intraday markets to handle excess generated wind and difficult conditions resulting from wind energy. The impact of wind energy on market prices in various markets such as day-ahead and intraday markets have been the main topic of many papers, including $[5,42,43]$. Therefore, the question of acceptable and proper market design has frequently been studied, particularly in [44-47]. The majority of these contributions capture attention either in the spot market or the balancing market. A noticeable exception is [47], which simulates the link thoroughly and relates the intraday and the balancing markets. The fundamental aspect which this paper has focused on is the liquidity under a wide range of variates of market designs, for spot as well as for intraday markets. The main purpose of any improvement process in the market is to achieve better conditions in market design which should improve and enhance the markets' efficiency.

Many methods have been proposed to investigate balance like [48] which investigates the control and direct impact of prices and paradigms in an oligopolistic model. Game theoretical modeling for evaluating the ability of incentives to mitigate the electricity market or numerical results, [49] has investigated costs and revenues of the market.

According to previous studies, a kind of classification is proposed in this paper as shown in Figure 5 to enhance operation of the intraday market and therefore, reduce the useless effects of introducing wind power to the electricity network including the uncertainty and unpredictability of the wind farms' output power.

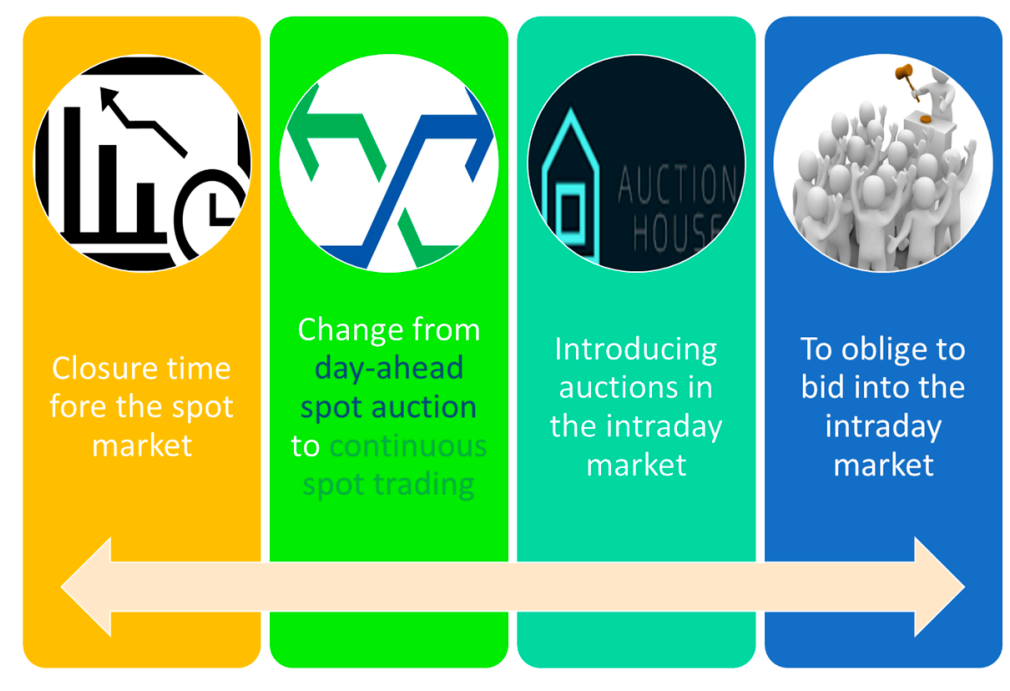

Figure 5. Classification for improving the functioning of the intraday market.

The aim of all the illustrated measures in Figure 5 is to ease the intraday readjustment for wind energy generations and reduce the cost. The first alternative among the four options would effectively promote some developments in comparison with the current conditions and circumstances, while it is not balanced with the most frequent operating hours and would promote trading costs. In the spot auction, changing the auction's closure time to 6 p.m. of yesterday sounds to be a second useful option since it prepares the market for all participants to clear their open positions as they occur even sooner than the physical delivery. This debate is reasonable only if constraints in liquidity are not included. 
From the British experience point of view, this alternative is not very satisfactory. It is likely to reduce liquidity and consequently push up the costs which are paid through wind Gencos. The third option is a beneficial compromise as well, together with flexible intraday transaction and bundling liquidity by announcing auctions in the intraday market.

The fourth option would impose limitations on the economic performance of the market players. Nevertheless, this would be advantageous for liquidity. However, the advantages of the fourth option are not so obvious. In the power systems with thermal units, renewable energy sources, demand, and participants may officially rectify their imbalances. When some formalities are imposed on the market, the players may submit their transaction bids with the same prices. Therefore, compulsory bids in the intraday market cannot work alone and might not be enough to promote the conditions for individual and independent wind energy generators.

\subsection{Spot Markets}

Recently, power exchange subject has become an indispensable tool for both power system operators and demand side investors to find the best way to reach their goals. According to [46], less than $25 \%$ of all energy electricity consumption is exchanged at the spot markets in most countries. In the German market, products at the day-ahead electricity market which range for the following day are bought and sold on the European Power Exchange (EPEX Spot) in Paris. Trading is performed in daily auctions. Participants prepare their price offers to propose them in the next-day market. After receiving all offers and finishing this stage, all offers are aggregated to establish supply and demand curves and consequently an integrated market price is used [50].

In day-ahead markets, participants prefer the situation in which the market is prevented from spreading and scattering liquidity in single trades happening over the whole trading time, which is two days in the UK, for instance. Besides, they opt for single auctions. While the volume of buying and selling in auctions has increased, liquidity in trading has reduced. The participant's interest to choose such a kind of auction and changes in auctions may be clarified by a planning process in utilities.

In different groups of recent studies the spot market is employed to cover the supply disruption by using a game theoretic model to reduce the loss [51]. In [52], a bi-level approach is presented to optimize spot-market operations. The solution is to employ stochastic approximation to maximize the profit of communicating with close neighbors in the electricity spot market.

\subsection{Intraday Markets}

By expanding the presence of wind farms and their power generations, day-ahead schedules have to be renewed in terms of new data arrival. Unit outages and changes in load estimation are included in the new information. Simplifying the problems such as linearizing bidding curves in intraday markets leads to the adjustment of impractical plans resulting from spot markets.

In this context, intraday markets can be designed as markets which run after submitting designs to the electricity system operators which are not postponed for a long time. The very low volumes of the energy traded in European intraday markets [46] may explain the probable inappropriate design of the market or untrustworthy market structure. Nevertheless, a closer look at various market behaviors is required.

\subsection{Balancing Markets and Reserve Markets}

The absolute guarantee of demand-supply balance has been the main subject in the literature. Energy reservoirs have always been used in this regard. When Generation Companies (Gencos) activities at the generation side are suspended or stopped, system operators propose their demands in the reserve markets to provide an energy balance by delivering reserve capacity to customers in real-time and compensating imbalance costs in similar markets. As a result, different researches have been carried out to develop various models for pricing these balancing services $[42,45,53]$. Transmission 
companies (Transcos) use reserves capacity to reduce the imbalances in real time. The major issues for integration of wind energy may be the amount of reserve and its price.

In [50], the control reserve power markets are defined. Accordingly, for Germany, control reserve powers are traded in Primary, Secondary, and Tertiary reserve power markets. Reserve capacities and prices including price offers are submitted by Gencos. Reserve capacities have a long time period which lasts from $4 \mathrm{~h}$ to 7 days. Different strategies in reserve markets for maximizing generator's profit and simulation results for analyzing effects on prices are obtained from the units' price offers.

In European countries, the primary market is cleared first, then the secondary and tertiary markets are cleared respectively. The day-ahead spot markets clearance is applied after auction for reserve. Therefore, past market's results vary from market to market which can be take into account from the decision maker's point of view. In [54], a mathematical form is presented to assess the resemblance between different markets or various intervals in an electricity market, which can also be a helpful multi-purpose tool in such fields of study.

Due to investigating recent studies to find the advancing frontiers of combining the two subjects of renewable energies and demand response programs in the current studies, Table 1 explains the classification of the proposed optimization models considering different types of market exchanges. Moreover, the direction and track process of researchers can be derived from this table.

Table 1. Taxonomy of different markets and relevant literature.

\begin{tabular}{|c|c|c|c|c|c|c|c|}
\hline \multirow{2}{*}{ Ref. } & \multicolumn{4}{|c|}{ Day-Ahead Market } & \multirow[t]{2}{*}{ Intraday Market } & \multirow[t]{2}{*}{ Balancing Market } & \multirow[t]{2}{*}{ DRX Market } \\
\hline & Two-stage & Multistage & Robust Programming & Chance Constrained & & & \\
\hline [55] & & $\checkmark$ & & & $\checkmark$ & & $\sqrt{ }$ \\
\hline [56] & & $\checkmark$ & & & $\checkmark$ & & $\checkmark$ \\
\hline [57] & & $\checkmark$ & & & $\checkmark$ & $\sqrt{ }$ & $\checkmark$ \\
\hline [58] & & & & & & $\checkmark$ & \\
\hline [59] & & $\sqrt{ }$ & & & & $\checkmark$ & \\
\hline [60] & & $\checkmark$ & & & & $\checkmark$ & \\
\hline [61] & & $\checkmark$ & & & $\sqrt{ }$ & $\checkmark$ & $\sqrt{ }$ \\
\hline [62] & $\checkmark$ & & & & $\checkmark$ & $\checkmark$ & $\checkmark$ \\
\hline [48] & $\checkmark$ & & & & $\checkmark$ & $\checkmark$ & \\
\hline [63] & $\sqrt{ }$ & & & & & & \\
\hline [64] & & & & & & $\sqrt{ }$ & \\
\hline [65] & & & & & $\sqrt{ }$ & & $\checkmark$ \\
\hline [66] & & & $\sqrt{ }$ & & & & \\
\hline [61] & $\checkmark$ & & & $\checkmark$ & & & \\
\hline [67] & $\checkmark$ & & & $\checkmark$ & & & \\
\hline [68] & & $\checkmark$ & & $\checkmark$ & & & \\
\hline [69] & & & & $\checkmark$ & & & \\
\hline [70] & $\sqrt{ }$ & & $\sqrt{ }$ & & & $\sqrt{ }$ & \\
\hline
\end{tabular}

\section{Various Demand Response Costs and Benefits}

Recently papers have discussed the positive and negatives aspects of implementing DRPs. In [35], a planning tool is explained to estimate the expected costs and benefits of DRPs. Engineers have become able to construct and develop models, receive various data from other kinds of commercial tools, conceive the results, work with a web interface and make a profit using this tool. The DR model can formulate Time of Use (TOU), Critical Peak Pricing (CPP), Peak Time Rebate (PTR), and Direct Load Control (DLC) programs for cost-benefit investigation. A model is employed for estimating the impact of price to investigate changes in the demand-side load curve in terms of changes in incentive payments. This proposed model calculates net present value and the rate of benefit versus cost through the program period. The next section discusses both the positive aspects expected from DR programs as well as the negative aspects.

\subsection{Benefit of $D R$}

Several reports have studied advantages of DR in energy systems with renewable energy resources. In [71] investigation and evaluation of the benefits of costumer's demand response are conducted in a smart power grid system. The measuring metrics and indices were established. The authors effectively derived real advantages from the indices. 
According to [72], microgrids should buy their required energy from a retailer independently by paying renewable energy generators and behave like an energy generator or an investor instead of being just a customer and imposing load. To optimize the program, an objective function is formulated from the system operator's point of view and maximized employing particle swarm optimization.

In Figure 6 [3] the benefits associated with DR are summarized; the DR benefits are clustered around four main collections: participant, market-wide, reliability, and market performance benefits. The benefits of DRPs are not only for the ones who get involved in programs; some are market-wide. Finally, market prices are reduced as a result of employing most of the infrastructure, for instance, reduction in units' demands with expensive electricity generation. DRPs exert a powerful effect on pushing down the market prices $[40,73]$. Furthermore, DRPs can expand short-term capacity through incentive-based programs which in sequence, leads to keeping down capacity costs. Reliability is considered as a subcategory of the DR benefits because it affects all the market. Due to the importance of reliability, it is considered an individual category. Through an accurately modeled DR program, participants can help to decrease the risk of outages. Consequently, participants diminish the risk of being faced to enforced outages and/or electricity interruption.

According to $[74,75]$, it can be concluded that the last subcategory of DRPs' benefits boosts electricity market performance. There will be more opportunities for DR program participants to have more alternatives in the electricity market even if retail competition is not accessible.

Participants can reduce their consumption as they can affect the market, especially with the IBPs and PBPs. One of the market performance enhancements is cutting down the price which changes frequently in the spot market. DR programs, particularly for heavy consumers, help bring down system operating costs and as a result of this action drop the market prices [6]. Since large-scale producers may have control over the market, implementing the DRPs or taking part in such programs mitigates the market power. The role of power generators as price makers in the market is mitigated by DR and consequently, power market indices are reduced significantly [76].

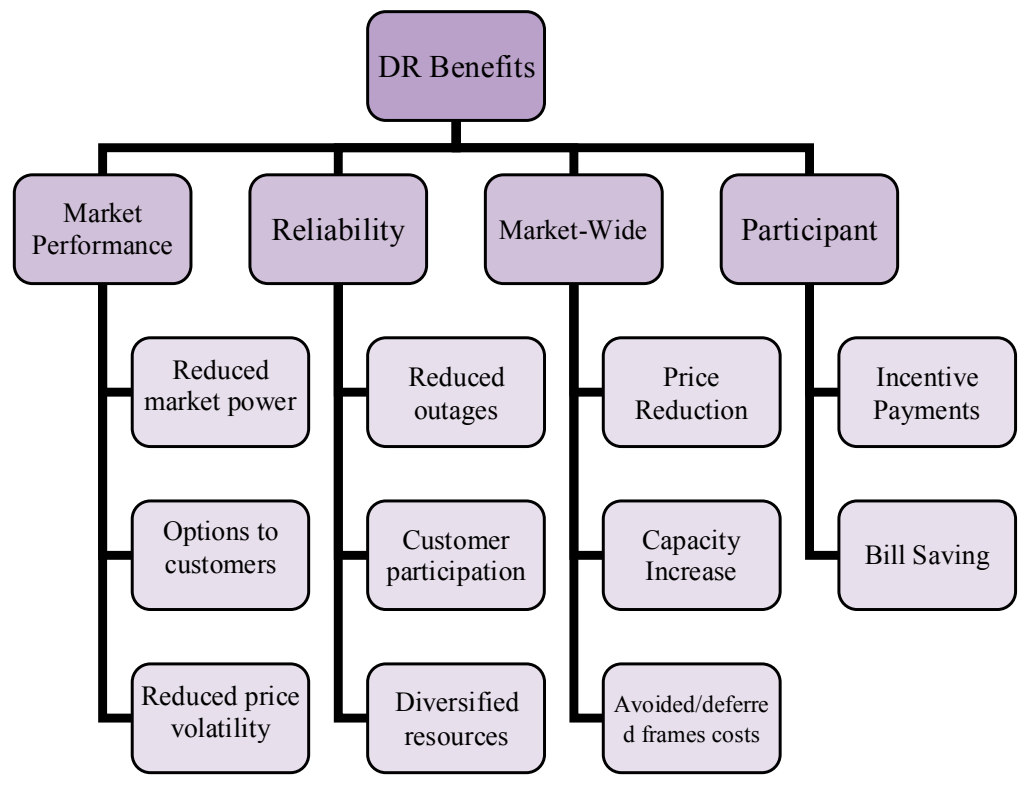

Figure 6. Classification of demand response (DR) benefits [3].

In environmental benefit discussions, DR programs and renewable energy resources have always been useful keys to address these concerns and include useful applications as a result of new electrical infrastructures including power generation units and power transmission lines, qualitative development of the environment through optimal and effective application of resources, 
and preventing depletion of natural resources. This has become one of the main concerns of governments, organizations and researchers [41].

In [4], DR benefits are divided into seven categories: in terms of economy, environmental condition, impact of market efficiency, price issue, expanding customer services, lower cost energy system and services, the concept of risk management and reliability.

\subsection{Cost of $D R$}

Every DRP includes various types of costs; Figure 7 depicts clustering of DRP costs, where both DRP implementers and participants at the demand side suffer from initial and running costs [77]. Participants might be required to buy some new digital technologies, in addition to installing and deriving DR programs: intelligent thermostats, controlling peak loads, energy management systems, and in place generation units. A set of response decisions as a plan or strategy requires scheduling therefore it can be implemented as an event. These basic and primary costs are usually born by customers who take part in programs; nevertheless, high-tech assistance and other paraphernalia should be supplied through the program.

Customers covering costs are those related to events. Based on the DR plan, these costs are different. One of running costs which is imposed on participants is an inconvenience. Sometimes the thermostat must be turned off and on by costumers when it does not operate correctly. Other relevant business costs are lost which might be considered as business integration. Rescheduling industrial processes and activities might be classified as the last running costs of participants. If a customer who is involved in a DR program employs a production unit instead of an onsite generation unit, operating and maintenance costs or fuel cost should be considered.

The DR operator has to decide based on the initial and running costs of the power system. Metering and communication frames and structure costs are included in the majority of DRPs in terms of initial costs. Advanced smart electricity meters are used to read and measure energy usage in specific time intervals, for instance, hourly real time pricings should be employed through demand side participants. Administration and management costs of the program should be considered in the running costs of DRPs. In addition, incentive payments relative to running costs of DRP providers are assumed. Before employing the large majority of DRPs, improving the billing system is essential.

Definition of the primary cost item before applying DRPs is a useful effect of this program and is taught to acceptable and suitable customers. Different DRP alternatives should be described to participants, and also response strategies should be properly explained. Participant educations make a considerable impact on DR program success. Effective marketing proves of great value to draw new participants and tempt them into taking part in programs. Moreover, a comprehensive evaluation and accurate measurement of DRPs for implementing a practical approach to achieve the intended objectives of the programs is important [77].

From another point of view, DR costs are well explained and defined in terms of two groups. The initial implementation includes program design, marketing, metering communication, and business integration. Besides, incentive payments, administrative, maintenance, and customer opportunity are included in the second group [4].

In general, costs can be determined by two parties: the industrial employments that deliver DRPs and its provisions that create the infrastructure require to support DR [77]. According to [78] the costs for the Demand Response program operators are divided into three specific categories as shown in Figure 8. In summary, the paper depicts that variable costs are the primary and main type of cost, while investments and annual fixed costs are too slight or small to be important. The results of an advantageous calculation illustrate that Demand Response can be economical:

Investments: To expand Demand Response capacity through implemented DRPs, several worthwhile investments have to be promoted. Measurement and communication infrastructure and control advanced technologies should be installed [79,80]. Moreover, enterprise software should be developed with the aim of achieving enablement of load control. This type of costs depends on the kind 
of DRP. The investments related to process technologies are minimal for industrial employments [81] because many businesses have already employed metering and communication frames, as well as control and software technologies.

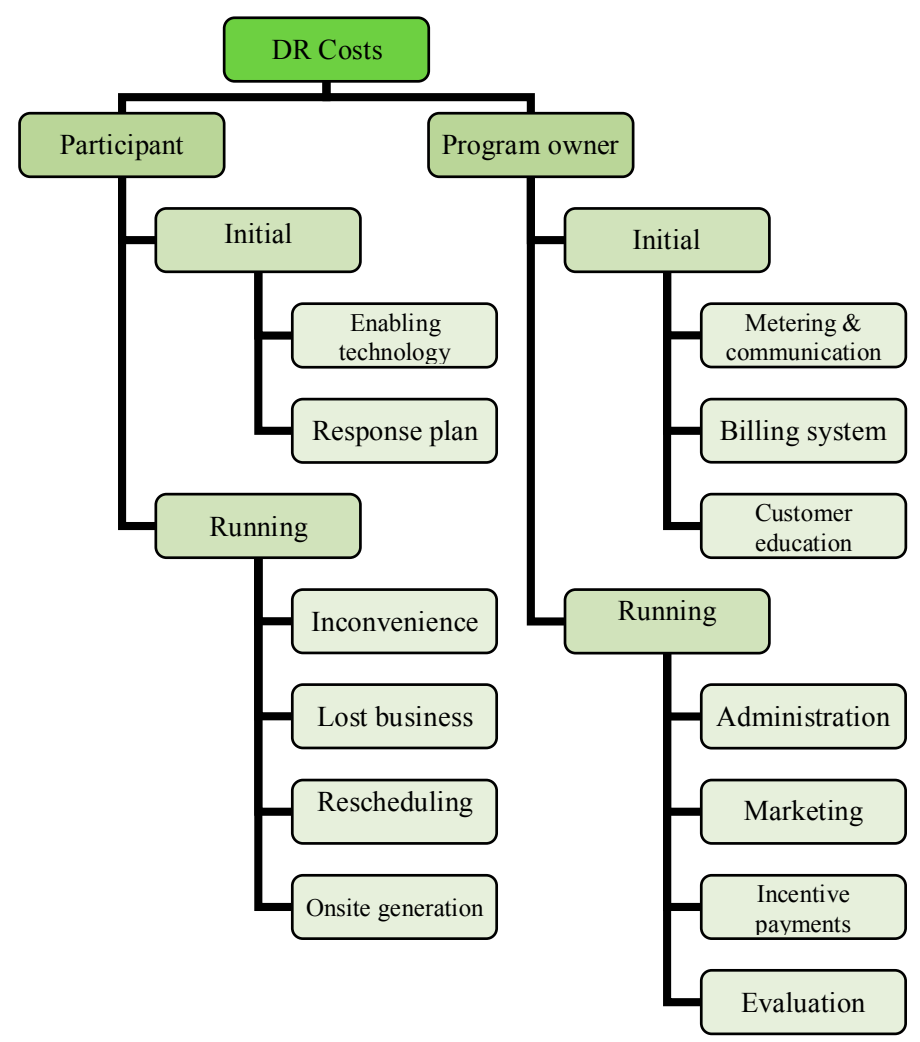

Figure 7. Classification of DR costs [3].

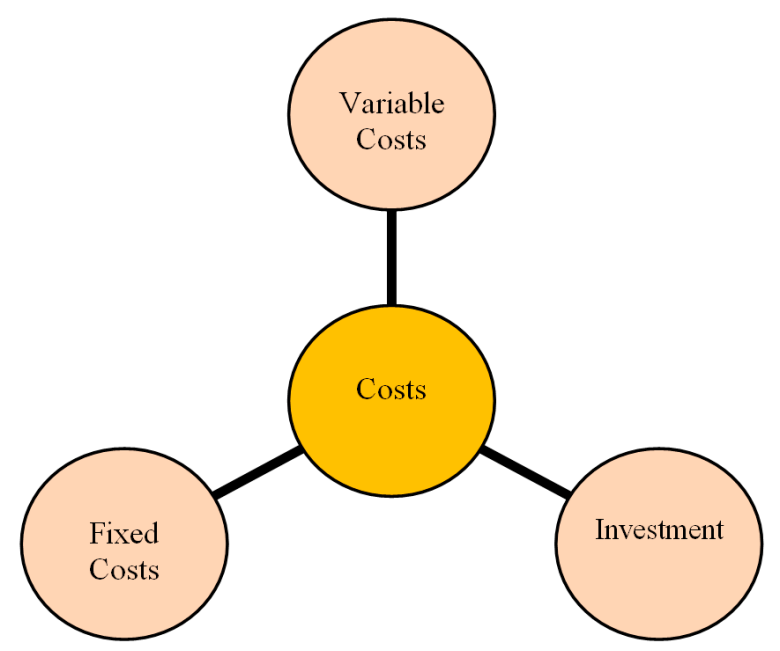

Figure 8. Classification Costs for system operators are subdivided into three major categories [78].

Fixed Costs: Fixed costs are separated into information, contract fee, and control costs [82]. Compiling data and facts for implementing decisions leads to Information costs. Transaction costs or contract fee costs are imposed through communication costs, occurring through the implementation and regulation of processes containing DR. These three kinds of fixed costs significantly cause costs as 
personnel. Moreover, data exchange between business and a Demand Response provider may result in fixed costs [81].

Classification of DR costs and benefits for system operators are demonstrated in Figure 9.

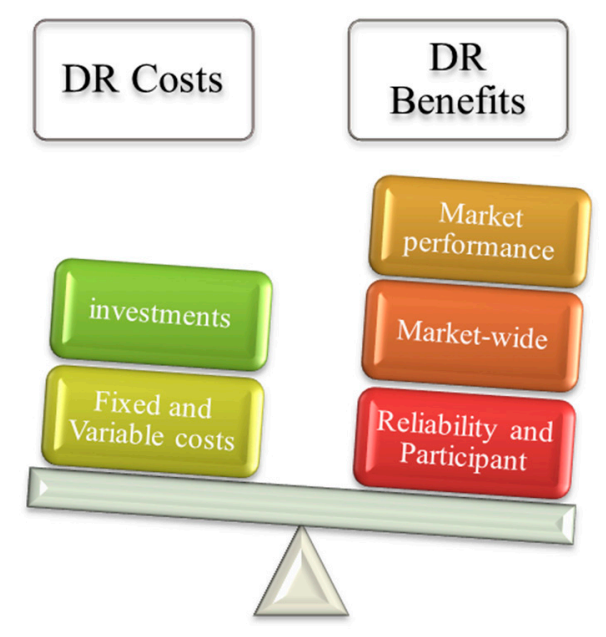

Figure 9. Classification DR costs and benefits for system operators at one look.

Variable costs: The U.S. Department of Energy explains the variable costs in terms of opportunity costs. It can be considered that variable costs arise from technologies to a large degree, since short-term technologies do not naturally affect business products.

\section{Conclusions}

In this thorough review paper of DR and renewable energies, the latest modifications and reformations in DR definition and classifications were investigated. Besides this, benefits and expenses were categorized extensively. DR affects market prices tremendously and brings them down, enhances system reliability, improves flexibility of the system, and smoothes electricity prices. To employ DR programs, both customers and program operators face a variety of costs. Reduction in peak load and demand elasticity are items for measuring the practical profits of DRPs. Although latest researches have illustrated more and considerable profits from DR programs, program assessment studies have proven significant benefits of these practical programs. Many related researches were performed previously but they are scattered. An in-depth review of the very recently published reports about DRPs associated with renewable energies was presented to gather this valuable information in one review paper. Moreover, using DR programs and renewable resources in smart grids and the power system or in various electricity markets was investigated. In addition, a comprehensive classification of recent research methods for optimization in the intraday market, day-ahead market, balancing market, and DRX market was proposed.

Acknowledgments: João P. S. Catalão acknowledges the support by FEDER funds through COMPETE 2020 and by Portuguese funds through FCT, under Projects SAICT-PAC/0004/2015-POCI-01-0145-FEDER-016434, POCI-01-0145-FEDER-006961, UID/EEA/50014/2013, UID/CEC/50021/2013, and UID/EMS/00151/2013, and also funding from the EU 7th Framework Programme FP7/2007-2013 under GA no. 309048.

Author Contributions: All authors have worked on this manuscript together and all authors have read and approved the final manuscript.

Conflicts of Interest: The authors declare no conflict of interest. 


\section{References}

1. Heydarian-Forushani, E.; Moghaddam, M.P.; Sheikh-El-Eslami, M.K.; Shafie-khah, M.; Catalao, J.P. Investigating the effects of flexible load in the grid integration of wind power. In Proceedings of the 2014 IEEE PES T\&D Conference and Exposition, Chicago, IL, USA, 14-17 April 2014; pp. 1-5.

2. Chen, R.; Botterud, A.; Sun, H.; Wang, Y. A bilateral reserve market for variable generation: Concept and implementation. In Proceedings of the Power and Energy Society General Meeting (PESGM), Boston, MA, USA, 17-21 July 2016; pp. 1-5.

3. Albadi, M.H.; El-Saadany, E.F. A summary of demand response in electricity markets. Electr. Power Syst. Res. 2008, 78, 1989-1996. [CrossRef]

4. Aghaei, J.; Alizadeh, M.-I. Demand response in smart electricity grids equipped with renewable energy sources: A review. Renew. Sustain. Energy Rev. 2013, 18, 64-72. [CrossRef]

5. Lund, P.D.; Lindgren, J.; Mikkola, J.; Salpakari, J. Review of energy system flexibility measures to enable high levels of variable renewable electricity. Renew. Sustain. Energy Rev. 2015, 45, 785-807. [CrossRef]

6. Wang, Q.; Zhang, C.; Ding, Y.; Xydis, G.; Wang, J.; Østergaard, J. Review of real-time electricity markets for integrating distributed energy resources and demand response. Appl. Energy 2015, 138, 695-706. [CrossRef]

7. Wang, F.; Xu, H.; Xu, T.; Li, K.; Shafie-khah, M.; Catalão, J.P. The values of market-based demand response on improving power system reliability under extreme circumstances. Appl. Energy 2017, 193, $220-231$. [CrossRef]

8. Chen, H.; Cong, T.N.; Yang, W.; Tan, C.; Li, Y.; Ding, Y. Progress in electrical energy storage system: A critical review. Prog. Nat. Sci. 2009, 19, 291-312. [CrossRef]

9. Zhou, D.; Zhao, C.-Y.; Tian, Y. Review on thermal energy storage with phase change materials (PCMs) in building applications. Appl. Energy 2012, 92, 593-605. [CrossRef]

10. O’Dwyer, C.; Ryan, L.; Flynn, D. Efficient Large-Scale Energy Storage Dispatch: Challenges in Future High Renewables Systems. IEEE Trans. Power Syst. 2017, 32, 3439-3450. [CrossRef]

11. Lund, H.; Salgi, G. The role of compressed air energy storage (CAES) in future sustainable energy systems. Energy Convers. Manag. 2009, 50, 1172-1179. [CrossRef]

12. Wang, Y.; Dvorkin, Y.; Fernandez-Blanco, R.; Xu, B.; Qiu, T.; Kirschen, D. Look-Ahead Bidding Strategy for Energy Storage. IEEE Trans. Sustain. Energy 2017, 8, 1106-1117. [CrossRef]

13. Pandžić, H.; Wang, Y.; Qiu, T.; Dvorkin, Y.; Kirschen, D.S. Near-optimal method for siting and sizing of distributed storage in a transmission network. IEEE Trans. Power Syst. 2015, 30, 2288-2300. [CrossRef]

14. Nikolova, S.; Causevski, A.; Al-Salaymeh, A. Optimal operation of conventional power plants in power system with integrated renewable energy sources. Energy Convers. Manag. 2013, 65, 697-703. [CrossRef]

15. Ye, B.; Zhang, K.; Jiang, J.; Miao, L.; Li, J. Toward a 90\% renewable energy future: A case study of an island in the South China Sea. Energy Convers. Manag. 2017, 142, 28-41. [CrossRef]

16. Ye, B.; Yang, P.; Jiang, J.; Miao, L. Feasibility and economic analysis of a renewable energy powered special town in China. Resour. Conserv. Recycl. 2017, 121, 40-50. [CrossRef]

17. Oren, S.S. Generation adequacy via call options obligations: Safe passage to the promised land. Electr. J. 2005, 18, 28-42. [CrossRef]

18. Heo, D.-Y.; Tesfatsion, L. Standardized contracts with swing for the market-supported procurement of energy and reserve: Illustrative examples. In Proceedings of the Power and Energy Society General Meeting (PESGM), Denver, CO, USA, 26-30 July 2015; pp. 1-30.

19. Fattler, S.; Pellinger, C. The value of flexibility and the effect of an integrated European Intraday-Market. In Proceedings of the 2016 13th International Conference on the European Energy Market (EEM), Porto, Portugal, 6-9 June 2016; pp. 1-5.

20. Hansen, J.; Somani, A.; Sun, Y.; Zhang, Y. Auction design for power markets based on standardized contracts for energy and reserves. In Proceedings of the Power and Energy Society General Meeting (PESGM), Boston, MA, USA, 17-21 July 2016; pp. 1-5.

21. Gil, E.; Aravena, I. Evaluating the capacity value of wind power considering transmission and operational constraints. Energy Convers. Manag. 2014, 78, 948-955. [CrossRef] 
22. Tabone, M.D.; Callaway, D.S. Modeling variability and uncertainty of photovoltaic generation: A hidden state spatial statistical approach. IEEE Trans. Power Syst. 2015, 30, 2965-2973. [CrossRef]

23. Alhaider, M.; Fan, L.; Miao, Z. Benders Decomposition for stochastic programming-based PV/Battery/HVAC planning. In Proceedings of the Power and Energy Society General Meeting (PESGM), Boston, MA, USA, 17-21 July 2016; pp. 1-5.

24. Wang, D.; Guan, X.; Wu, J.; Li, P.; Zan, P.; Xu, H. Integrated energy exchange scheduling for multimicrogrid system with electric vehicles. IEEE Trans. Smart Grid 2016, 7, 1762-1774. [CrossRef]

25. Wang, D.; Coignard, J.; Zeng, T.; Zhang, C.; Saxena, S. Quantifying electric vehicle battery degradation from driving vs. vehicle-to-grid services. J. Power Sources 2016, 332, 193-203. [CrossRef]

26. Wang, D.; Gao, J.; Li, P.; Wang, B.; Zhang, C.; Saxena, S. Modeling of plug-in electric vehicle travel patterns and charging load based on trip chain generation. J. Power Sources 2017, 359, 468-479. [CrossRef]

27. Chen, W.; Yan, H.; Pei, X.; Wu, B. Probabilistic load flow calculation in distribution system considering the stochastic characteristic of wind power and electric vehicle charging load. In Proceedings of the 2016 IEEE PES Asia-Pacific Power and Energy Engineering Conference (APPEEC), Xi'an, China, 25-28 October 2016; pp. 1861-1866.

28. Amid, P.; Crawford, C. Cumulant-based probabilistic load flow analysis of wind power and electric vehicles. In Proceedings of the 2016 International Conference on Probabilistic Methods Applied to Power Systems (PMAPS), Beijing, China, 16-20 October 2016; pp. 1-6.

29. Zhang, Q.; Ju, F.; Zhang, S.; Deng, W.; Wu, J.; Gao, C. Power Management for Hybrid Energy Storage System of Electric Vehicles Considering Inaccurate Terrain Information. IEEE Trans. Autom. Sci. Eng. 2017, 14, 608-618. [CrossRef]

30. Heydarian-Forushani, E.; Golshan, M.E.H.; Shafie-khah, M.; Catalão, J.P.S. Impacts of stochastic demand response resource scheduling on large scale wind power integration. In Proceedings of the 2015 Australasian Universities Power Engineering Conference (AUPEC), Wollongong, Australia, 27-30 September 2015; pp. 1-6.

31. Wang, D.; Kalathil, D.; Poolla, K.; Guan, X. Coordination of wind power and flexible load through demand response options. In Proceedings of the 2015 IEEE 54th Annual Conference on Decision and Control (CDC), Osaka, Japan, 15-18 December 2015; pp. 7226-7231.

32. Tomiyama, K.; Kawano, Y.; Hashimoto, T.; Ohtsuka, T. Real-time price optimization for load frequency control in electric power systems with wind farms. In Proceedings of the 2016 SICE International Symposium on Control Systems (ISCS), Nagoya, Japan, 7-10 March 2016; pp. 1-6.

33. Wei, M.; Zhong, J. Scenario-based real-time demand response considering wind power and price uncertainty. In Proceedings of the 2015 12th International Conference on the European Energy Market (EEM), Lisbon, Portugal, 19-22 May 2015; pp. 1-5.

34. Parvania, M.; Fotuhi-Firuzabad, M. Integrating load reduction into wholesale energy market with application to wind power integration. IEEE Syst. J. 2012, 6, 35-45. [CrossRef]

35. Yousefi, A.; Iu, H.H.-C.; Fernando, T.; Trinh, H. An approach for wind power integration using demand side resources. IEEE Trans. Sustain. Energy 2013, 4, 917-924. [CrossRef]

36. Heydarian-Forushani, E.; Moghaddam, M.P.; Sheikh-El-Eslami, M.K.; Shafie-khah, M.; Catalão, J.P.S. A stochastic framework for the grid integration of wind power using flexible load approach. Energy Convers. Manag. 2014, 88, 985-998. [CrossRef]

37. IEA. Strategic Plan for the IEA Demand-Side Management Program 2014-2020. Available online: http:/ / www.iea.org. (accessed on 29 January 2017).

38. International Energy Agency. The Power to Choose-Demand Response in Liberalized Electricity Markets; OECD: Paris, France, 2003.

39. Aalami, H.A.; Moghaddam, M.P.; Yousefi, G.R. Demand response modeling considering Interruptible/Curtailable loads and capacity market programs. Appl. Energy 2010, 87, 243-250. [CrossRef]

40. Asensio, M.; Contreras, J. Risk-constrained optimal bidding strategy for pairing of wind and demand response resources. IEEE Trans. Smart Grid 2017, 8, 200-208. [CrossRef]

41. Estimating Demand Response Load Impacts: Evaluation of Baseline Loadmodels for Non-Residential Buildings in California. Available online: http:/ / goo.gl/bKUIcm (accessed on 29 January 2017). 
42. Hirth, L.; Ueckerdt, F.; Edenhofer, O. Integration costs revisited-An economic framework for wind and solar variability. Renew. Energy 2015, 74, 925-939. [CrossRef]

43. Spiecker, S.; Weber, C. The future of the European electricity system and the impact of fluctuating renewable energy-A scenario analysis. Energy Policy 2014, 65, 185-197. [CrossRef]

44. Ketter, W.; Collins, J.; Weerdt, M. The 2016 power trading agent competition. In Proceedings of the PES Innovative Smart Grid Technologies Conference Europe (ISGT-Europe), Ljubljana, Slovenia, 9-12 October 2016; pp. 1-6.

45. Vandezande, L.; Meeus, L.; Belmans, R.; Saguan, M.; Glachant, J.-M. Well-functioning balancing markets: A prerequisite for wind power integration. Energy Policy 2010, 38, 3146-3154. [CrossRef]

46. Weber, C. Adequate intraday market design to enable the integration of wind energy into the European power systems. Energy Policy 2010, 38, 3155-3163. [CrossRef]

47. Maupas, F. Analyse de L'impact économique de L'aléa éolien sur la Gestion de L'équilibre Production Consommation d'un Système électrique. Ph.D. Thesis, University of Paris XI, Paris, France, 2008.

48. Shafie-khah, M.; Shoreh, M.H.; Siano, P.; Neyestani, N.; Yazdani-Damavandi, M.; Catalão, J.P.S. Oligopolistic behavior of wind power producer in electricity markets including Demand Response Resources. In Proceedings of the Power and Energy Society General Meeting (PESGM), Boston, MA, USA, 17-21 July 2016; pp. 1-5.

49. Shafie-khah, M.; Fitiwi, D.Z.; Catalão, J.P.S.; Heydarian-Forushani, E.; Golshan, M.E.H. Simultaneous participation of Demand Response aggregators in ancillary services and Demand Response eXchange markets. In Proceedings of the 2016 IEEE/PES Transmission and Distribution Conference and Exposition (T\&D), Dallas, TX, USA, 3-5 May 2016; pp. 1-5.

50. Skiba, L.; Maaz, A.; Moser, A. Agent-based price simulation of the day-ahead-spot-market and markets for control reserve power. In Proceedings of the 2016 13th International Conference on the European Energy Market (EEM), Porto, Portugal, 6-9 June 2016; pp. 1-5.

51. Feng-min, Y.; Shan, L.; Wen-hao, N. Spot market coping with supply disruption under supply chains competition. In Proceedings of the 2016 Chinese Control and Decision Conference (CCDC), Yinchuan, China, 28-30 May 2016; pp. 6003-6008.

52. Wollega, E.D.; Ghosh, S.; Squillante, M.S. Bi-level stochastic approximation for joint optimization of hydroelectric dispatch and spot-market operations. In Proceedings of the Winter Simulation Conference (WSC), Washington, DC, USA, 11-14 December 2016; pp. 1769-1780.

53. Kazemi, M.; Mohammadi-Ivatloo, B.; Ehsan, M. Risk-constrained strategic bidding of GenCos considering demand response. IEEE Trans. Power Syst. 2015, 30, 376-384. [CrossRef]

54. Hajibandeh, N.; Sheikh-El-Eslami, M.K.; Aminnejad, S.; Shafie-Khah, M. Resemblance measurement of electricity market behavior based on a data distribution model. Int. J. Electr. Power Energy Syst. 2016, 78, 547-554. [CrossRef]

55. Wu, H.; Shahidehpour, M.; Alabdulwahab, A.; Abusorrah, A. Demand Response Exchange in the Stochastic Day-Ahead Scheduling With Variable Renewable Generation. IEEE Trans. Sustain. Energy 2015, 6, 516-525. [CrossRef]

56. Nasrolahpour, E.; Ghasemi, H. A stochastic security constrained unit commitment model for reconfigurable networks with high wind power penetration. Electr. Power Syst. Res. 2015, 121, 341-350. [CrossRef]

57. Pei, W.; Du, Y.; Deng, W.; Sheng, K.; Xiao, H.; Qu, H. Optimal Bidding Strategy and Intramarket Mechanism of Microgrid Aggregator in Real-Time Balancing Market. IEEE Trans. Ind. Inform. 2016, 12, 587-596. [CrossRef]

58. Jafari, A.M.; Zareipour, H.; Schellenberg, A.; Amjady, N. The Value of Intra-Day Markets in Power Systems with High Wind Power Penetration. IEEE Trans. Power Syst. 2014, 29, 1121-1132. [CrossRef]

59. Hu, Y.; Morales, J.M.; Pineda, S.; Sánchez, M.J.; Solana, P. Dynamic multi-stage dispatch of isolated wind-diesel power systems. Energy Convers. Manag. 2015, 103, 605-615. [CrossRef]

60. Zugno, M.; Conejo, A.J. A robust optimization approach to energy and reserve dispatch in electricity markets. Eur. J. Oper. Res. 2015, 247, 659-671. [CrossRef]

61. Wang, Q.; Guan, Y.; Wang, J. A Chance-Constrained Two-Stage Stochastic Program for Unit Commitment with Uncertain Wind Power Output. IEEE Trans. Power Syst. 2012, 27, 206-215. [CrossRef] 
62. Beraldi, P.; Conforti, D.; Violi, A. A two-stage stochastic programming model for electric energy producers. Comput. Oper. Res. 2008, 35, 3360-3370. [CrossRef]

63. Yazdani-Damavandi, M.; Neyestani, N.; Shafie-khah, M.; Contreras, J.; Catalao, J.P. Strategic Behavior of Multi-Energy Players in Electricity Markets as Aggregators of Demand Side Resources using a Bi-level Approach. IEEE Trans. Power Syst. 2017. [CrossRef]

64. Damavandi, M.Y.; Moghaddam, M.P.; Haghifam, M.-R.; Shafie-khah, M.; Catalão, J.P. Modeling Reserve Ancillary Service as Virtual Energy Carrier in Multi-Energy Systems. In Proceedings of the 6th Doctoral Conference on Computing, Electrical and Industrial Systems, Lisbon, Portugal, 13-15 April 2015; pp. 431-439.

65. Heydarian-Forushani, E.; Shafie-Khah, M.; Damavandi, M.Y.; Catalão, J.P. Optimal Participation of DR Aggregators in Day-Ahead Energy and Demand Response Exchange Markets. In Proceedings of the 5th Doctoral Conference on Computing, Electrical and Industrial Systems, Lisbon, Portugal, 7-9 April 2014; pp. 353-360.

66. Martinez-Mares, A.; Fuerte-Esquivel, C.R. A robust optimization approach for the interdependency analysis of integrated energy systems considering wind power uncertainty. IEEE Trans. Power Syst. 2013, 28, 3964-3976. [CrossRef]

67. Zhang, H.; Li, P. Chance constrained programming for optimal power flow under uncertainty. IEEE Trans. Power Syst. 2011, 26, 2417-2424. [CrossRef]

68. Summers, T.; Warrington, J.; Morari, M.; Lygeros, J. Stochastic optimal power flow based on convex approximations of chance constraints. In Proceedings of the Power Systems Computation Conference (PSCC), Wroclaw, Poland, 18-22 August 2014; pp. 1-7.

69. Wu, H.; Shahidehpour, M.; Li, Z.; Tian, W. Chance-constrained day-ahead scheduling in stochastic power system operation. IEEE Trans. Power Syst. 2014, 29, 1583-1591. [CrossRef]

70. Heydarian-Forushani, E.; Golshan, M.E.H.; Moghaddam, M.P.; Shafie-khah, M.; Catalão, J.P.S. Robust scheduling of variable wind generation by coordination of bulk energy storages and demand response. Energy Convers. Manag. 2015, 106, 941-950. [CrossRef]

71. Jingmeng, B.; Zeng, B.; Zhang, J.; Dunnan, L.; Ming, Z. Benefits comprehensive evaluation of demand response in SDN based on distant Grey Relational Analysis-Technique for Order Preference by Similarity to Ideal Solution. In Proceedings of the 2016 IEEE PES Asia-Pacific Power and Energy Engineering Conference (APPEEC), Xi'an, China, 25-28 October 2016; pp. 843-851.

72. Gheydi, M.; Farhadi, P.; Ghafari, R. The effect of demand response on operation of smart home energy system with renewable energy resources. In Proceedings of the 2016 International Symposium on Fundamentals of Electrical Engineering (ISFEE), Bucharest, Romania, 30 June-2 July 2016; pp. 1-6.

73. Nguyen, D.T.; Nguyen, H.T.; Le, L.B. Dynamic Pricing Design for Demand Response Integration in Power Distribution Networks. IEEE Trans. Power Syst. 2016, 31, 3457-3472. [CrossRef]

74. Dietrich, K.; Latorre, J.M.; Olmos, L.; Ramos, A. Demand response in an isolated system with high wind integration. IEEE Trans. Power Syst. 2012, 27, 20-29. [CrossRef]

75. Vardakas, J.S.; Zorba, N.; Verikoukis, C.V. A survey on demand response programs in smart grids: Pricing methods and optimization algorithms. IEEE Commun. Surv. Tutor. 2015, 17, 152-178. [CrossRef]

76. Soleymani, S.; Hajibandeh, N.; Shafie-khah, M.; Siano, P.; Lujano-Rojas, J.M.; Catalão, J.P.S. Impacts of Demand Response on oligopolistic behavior of electricity market players in the day-ahead energy market. In Proceedings of the Power and Energy Society General Meeting (PESGM), Boston, MA, USA, 17-21 July 2016; pp. 1-5.

77. Qdr, Q. Benefits of Demand Response in Electricity Markets and Recommendations for Achieving Them, A Report to the United States Congress; U.S. Department of Energy: Washington, DC, USA, February 2006.

78. Kreuder, L.; Gruber, A.; von Roon, S. Quantifying the costs of Demand Response for industrial businesses. In Proceedings of the 39th Annual Conference of the IEEE Industrial Electronics Society, IECON 2013, Vienna, Austria, 10-13 November 2013; pp. 8046-8051.

79. Von Scheven, A.; Prelle, M. Lastmanagementpotenziale in der stromintensiven Industrie zur Maximierung des Anteils regenerativer Energien im bezogenen Strommix. In VDE-Kongress 2012; VDE VERLAG GmbH: Stuttgart, Deutschland, 2012.

80. Gils, H.C. Balancing of Intermittent Renewable Power Generation by Demand Response and Thermal Energy Storage. Ph.D. Thesis, University of Stuttgart, Baden-Württemberg, Germany, 2015. 
81. Paulus, M.; Borggrefe, F. The potential of demand-side management in energy-intensive industries for electricity markets in Germany. Appl. Energy 2011, 88, 432-441. [CrossRef]

82. Graeber, D.; Kleine, A. The combination of forecasts in the trading of electricity from renewable energy sources. J. Bus. Econ. 2013, 83, 409-435. [CrossRef] 